


\section{O Lobo Mau, Pinóquio e as Irmãs Más como imagens transgêneras em Shrek: traços pedagógicos}

BELIDSON DIAS BEZERRA JUNIOR

ALICE MARIA VASCONCELOS LARA

Resumo

Este artigo é o resultado parcial de um projeto de Iniciação Científica e parte de uma análise dos filmes Shrek, Shrek segundo e Shrek terceiro, especificamente das representações dos personagens Lobo Mau, Pinóquio e irmãs feias, que não se enquadram heteronormativamente nos binômios macho $\mathrm{x}$ fêmea e homem x mulher. A série Shrek transita entre o publico infantil e adulto, mas tem um conteúdo complexo que gera diferentes formas de expectação. Este trabalho reflete sobre essas questões por meio de uma abordagem pedagógica que incentiva o entendimento a categoria trans e o respeito aos gêneros trans.
Palavras-chave:

Cinema, educação da cultura visual, teoria queer 


\section{Abstract}

This paper is an initial result of an Institutional Research Project of an analysis of the movies Shrek, Shrek second and third, with a focus on representations of the following characters Bad Wolf, Pinocchio and the Ugly Sisters, which are not framed heteronormatively within an opposite binary such as male $\mathrm{x}$ female, man $\mathrm{x}$ woman. Shrek is an animation that moves between different audiences and generates different forms of spectatorships. This reflects about these issues through a pedagogical approach to encourage understandings and respect for the trope trans and for transgenders. 
Inicialmente gostaríamos esclarecer que "gênero trans" ou "transgênero", termo que será utilizado neste artigo, se refere aos gêneros que não estão classificados baseados entre a oposição binária macho $\mathrm{X}$ fêmea e homem $\mathrm{X}$ mulher, mas transversalmente a elas percorrem e podem usar parte desses pólos identitárias e da tensão normalizadora para se constituirem. Portanto os personagens escolhidos para a análise poderiam ser classificados em identidades mais fixas como a do travesti ou crossdresser entre outros, mas optamos pelo termo transgênero pelo seu caráter mais genérico, o que faz com que englobe as outras denominações. Mais ainda, ele foi nomeado por se tratar de uma palavra que designa uma situação de trânsito, de identidade à deriva, flutuante, como é próprio de alguns dos fenômenos aqui estudados.

\section{Shrek e seus personagens transgêneros}

Nos últimos anos foram lançados vários filmes de animação que lidam com a questão do gênero de uma forma quase anarquista como os Os Simpsons, Os Oblongs, Ren and Stimpy, O pato gay, Mission Hill.... Em relação a esses outros filmes, Shrek é inovador não só pela discussão que promove de alguns dos valores e representações relacionados à sexualidade e à questão do gênero, mas também por apresentar uma transitividade maior em relação ao público infantil e ao público adulto. Lançado em 2001, pela DreamWorks, o filme é todo feito em computação gráfica. Seu enorme sucesso possibilitou mais duas seqüências (ainda estão previstas outras duas), além da comercialização de vários produtos, como brinquedos, roupas, e jogos. Como se sabe, tal prática é comum na indústria do entretenimento, mas, em Shrek, chama a atenção que essa comercialização esteja baseada em personagens que escapam aos padrões de beleza (como ocorre, por exemplo, com o casal de protagonistas - um ogro e uma ogra) e aos padrões sexuais exigidos pela moral vigente (como é o caso dos personagens analisados neste trabalho).

Existem quatro representações que podem ser consideradas transgêneras em Shrek: a primeira delas é Pinóquio, cuja primeira fala no primeiro filme ("Eu sou um menino de verdade") e o fato de ver o nariz crescer cada vez que conta uma mentira confirmam a imagem apresentada no conto infantil que lhe deu origem e nas muitas adaptações que o mesmo conto sofreu no cinema e em outras formas de comunicação. A partir do segundo filme, no entanto, Pinóquio, um dos amigos do protagonista Shrek, 
vai demonstrar a sua identidade trans. Uma cena é exemplar nesse sentido: Um grupo de amigos de se reúne para salvar Shrek da prisão, Pinóquio se pendura por fios de marionetes e entra dentro da cela, mas não consegue alcançar Shrek, então pedem-lhe para contar uma mentira pois assim alcançarão Shrek pelo nariz para lhe entregar a chave. Lhe dizem :

- diga que esta usando roupas íntimas femininas.

Ele nega e então seu nariz cresce, logo seus amigos descobrem que ele está usando roupas íntimas femininas. O grupo não chega a rir, mas estranha o fato e ridiculariza o boneco. Pinóquio nega estar usando tais roupas mesmo quando elas são mostradas, e quanto mais ele nega mais seu nariz cresce. No terceiro filme, tal identidade e a ambigüidade do personagem se intensificam, como, por exemplo, na cena em que, ao assistir com seus amigos uma peça de teatro onde trabalha o Príncipe Encantado, Pinóquio afirma:

- Odeio amadores.

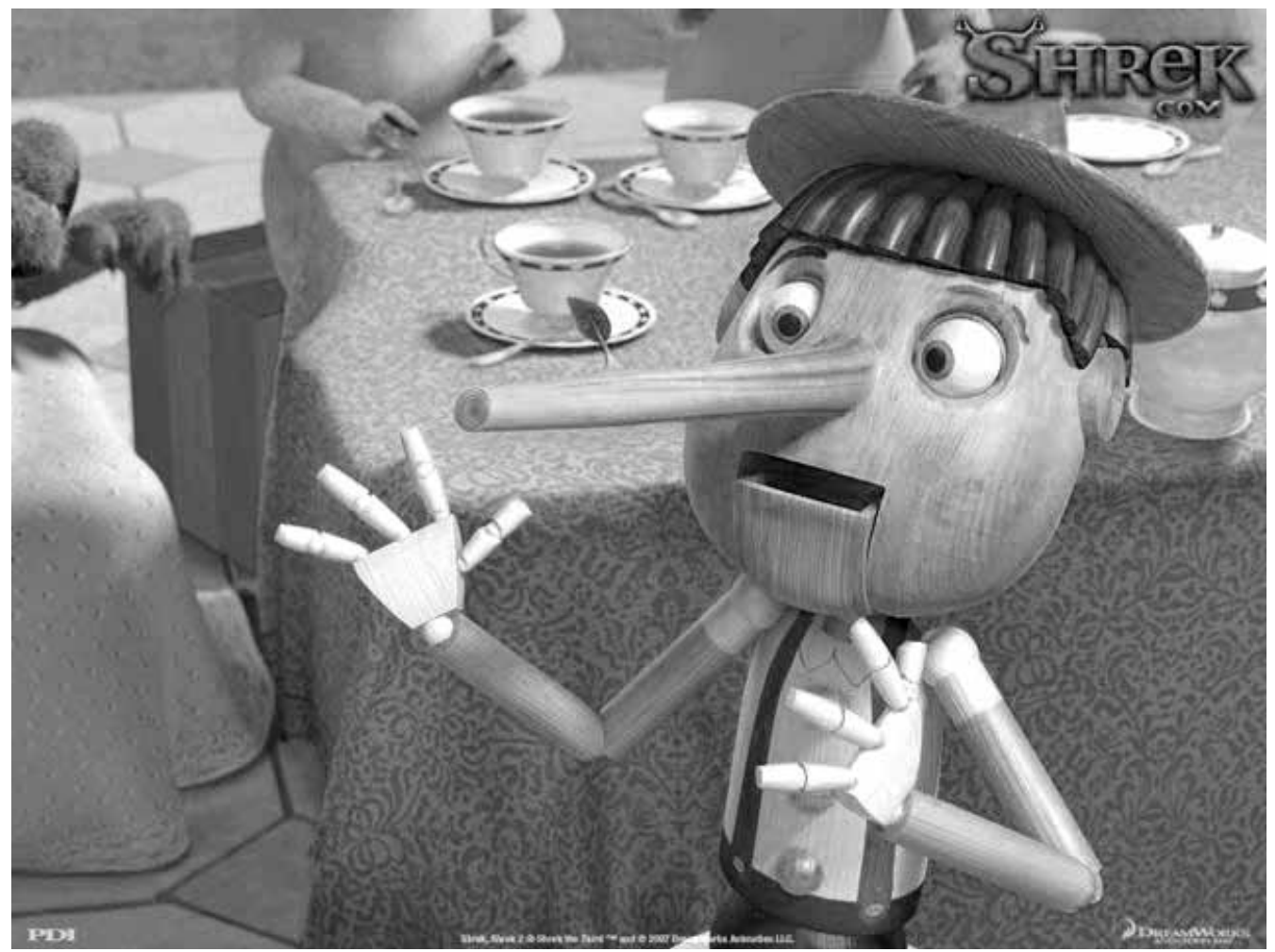




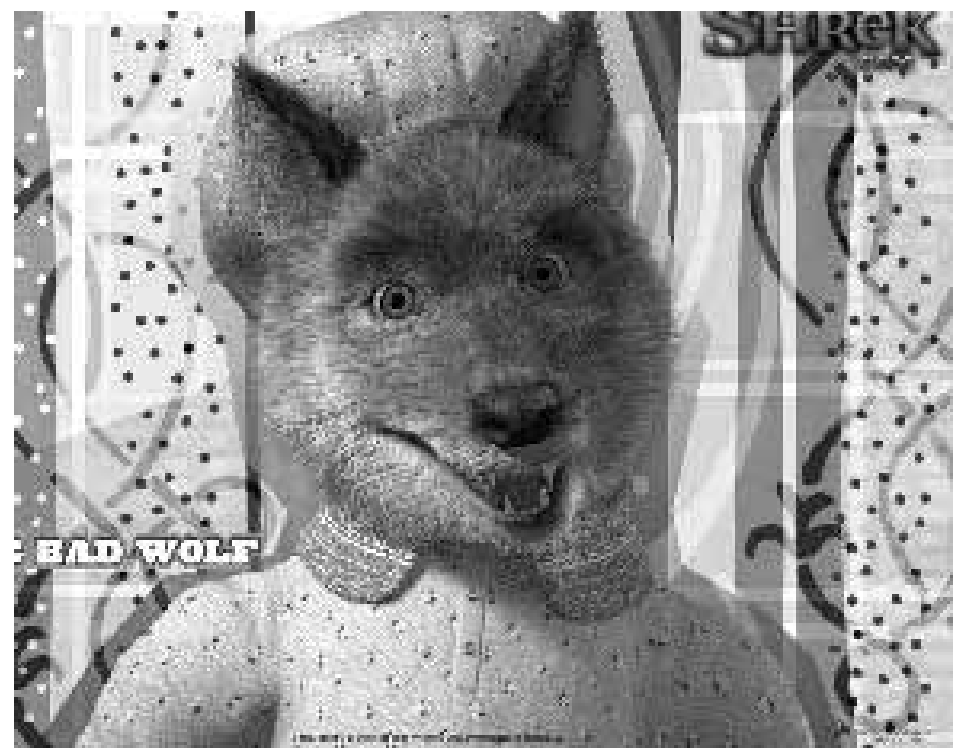

Nesse momento, seu nariz volta a crescer o que sugere que o personagem sente desejo pelo Príncipe. Existe, assim, um jogo entre o que se afirma e o que se apresenta materialmente. Pinóquio está incluído, portanto, numa estrutura reguladora da sexualidade homossexual que Sedgwick (2007) vai chamar de "armário", e cada "saída do armário" vai se configurar em implicações da posição social do personagem.

O segundo personagem transgênero é o Lobo Mau, uma apropriação de um dos personagens centrais dos contos infantis Chapeuzinho Vermelho e Os três porquinhos. Em Shrek, ele é outro dos amigos do protagonista e está sempre vestindo uma camisola rosa, apesar de ter voz masculina e agir como um macho, repetindo a cena do conto infantil em que o personagem se disfarça com as roupas da avó de Chapeuzinho Vermelho, de modo a enganar a menina. No segundo filme, a referência é mais evidente em relação aos três porquinhos, ou melhor, às porquinhas, que aparecem vestidas de biquíni numa revista que o Lobo Mau, deitado numa cama, está folheando. A ambigüidade, nesse caso, diz respeito ao desejo do personagem em relação às porquinhas expostas na revista, pois não se sabe se ele as deseja sexualmente ou se deseja simplesmente comê-las. Tal ambigüidade é reforçada pela vestimenta do personagem: sua camisola rosa ajuda a caracterizá-lo como identidade trans, o que gera estranhamento nos outros personagens, que não sabem como tratá-lo. 


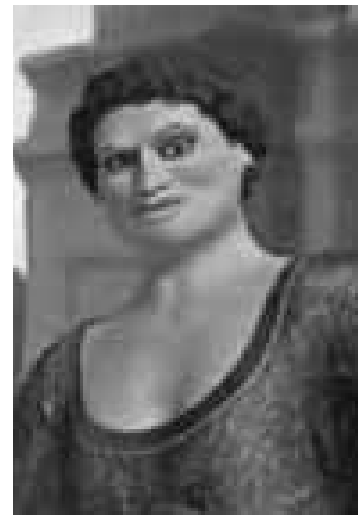

A terceira personagem trans que aparece em Shrek é Dóris, originalmente uma das irmãs feias e malvadas do conto infantil Cinderela. Essa personagem, que surge a partir do segundo filme, começa sua estória como garçonete de uma taberna freqüentada apenas por vilões. Quando Dóris aparece é sempre uma surpresa para o personagem que interage com ela, já que pensa ser ela uma mulher, e se assusta: sua voz é de homem (a dublagem de voz foi feita por um homem, inclusive). Ela é muito masculina, tem o corpo grande, musculoso, e seu peito não tem volume. Por outro lado, também usa muita maquiagem, um penteado feminino, e um vestido. Além disso, ela é apaixonada pelo Príncipe Encantado, a ponto de, no final do segundo filme, vir a beijá-lo a força, como se esse fosse um castigo para o príncipe, um dos vilões da estória, e que, por sinal, não gosta de ser beijado.

No terceiro filme, Dóris é uma dama de honra da Princesa Fiona, o que, por sua vez, faz com que ela ocupe papel de princesa, e reforça o contraste em relação às outras princesas: Rapunzel, Cinderela e Branca de Neve, aparentemente ocupando a representação de mulheres. Mas, enquanto as princesas são representadas como meninas fúteis, Dóris é sensata e gentil. A paixão pelo Príncipe Encantado também aparece no terceiro filme, mas quando Dóris manifesta seu desejo pelo vilão ("Ele me derrete mais que picolé no sol" é uma de suas falas), todos demonstram estar enojados. Outra das questões relacionadas ao transgênero diz respeito ao uso da ambigüidade do personagem para enganar os vilões. Assim, a parte "feminina" de Dóris (as pernas vestidas com meia calça e cinta liga) é usada, no momento em que as princesas precisam voltar para o castelo para salvar o reino, para seduzir os guardas, que, ao se aproximarem, ficam surpresos com sua aparência e terminam levando uma surra.

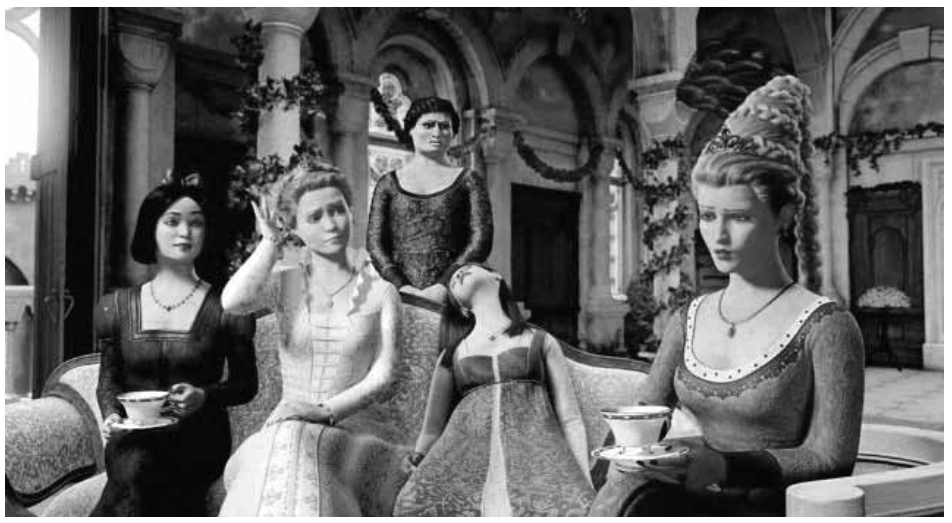


Dessa forma, o uso do corpo travestido para atrair o macho para uma armadilha, verdadeiro clichê de representação com fins cômicos, seja em novelas, em filmes ou em desenhos animados, é aproveitado em Shrek para reforçar a identidade trans.

Mabel é a quarta personagem trans a aparecer em Shrek, e a última a ser considerada nesta pesquisa. Ela é outra das irmãs feias de Cinderela e ocupa o lugar de Dóris na taverna, quando esta vai trabalhar no castelo. Mabel tem as mesmas características masculinas e femininas da irmã, com quem está brigada. Reconciliam-se com um cumprimento que geralmente os homens usam, dando socos no ombro uma da outra, mas quando Mabel soca Dóris, essa cai. Essas duas personagens, portanto, estão sempre jogando com o que é feminino e o que é masculino. Além disso, Dóris e Mabel representam o mal, na medida em que trabalham na taverna, local de encontro dos vilões, dos estranhos. São personagens representadas como abjetos, aqui entendidos pelas teorias de Butler que afirma:

Abjeto designa aqui precisamente aquelas zonas "inóspitas" e "inabitáveis" da vida social, que são, não obstantes, densamente povoadas por aqueles que não gozam do status de sujeito (...). Essa zona de instabilidade constitui o limite definidor do domínio do sujeito (...) o sujeito então é constituído através da força da exclusão. (BUTLER, 2008 p.19)

\section{Representação de preconceito ou aceitação da diferença?}

O que há de comum em todas essas quatro personagens? Elas só vão demonstrar seu gênero trans a partir do segundo filme, ou seja, o público parece ter sido "preparado" para o tipo de representação que ia aparecer nas seqüências do primeiro filme. Outra questão importante diz respeito ao tempo de exposição dessas personagens: elas aparecem por muito pouco tempo no filme, não fazem parte do enredo principal, antes estão dissolvidas em todas as representações heteronormativas e, muitas vezes, reforçam vários dos preconceitos do filme em relação à representação de gênero. Mas seria possível às representações trans protagonizar filmes desse tipo? Ou melhor: da forma como são apresentados, Pinóquio, Lobo Mau e as Irmãs Feias poderiam ser personagens principais de alguma estória infantil?

Como defende Sedgwick (2007), a revelação de identidade homossexual parece ficar cada vez mais cercada por uma atmosfera de "surpresa e prazer", ao invés de ficar menos estigmati- 
zada, devido as muitas conquistas dos homossexuais e o tempo de luta por direitos desse grupo. Desse modo, a revelação da identidade homossexual traz sempre uma carga de novidade e de diferença, mesmo que assim não seja, nem como identidade, nem como representação.

O transgênero é representado, em muitos momentos na história do cinema, de modo a reiterar o preconceito. No caso de Shrek, o espaço do humor, do riso, do ridículo, torna o assunto mais fácil para o público, seja ele trans ou normativo, o que pode ser considerado uma regressão, já que a representação dos transgêneros reafirma as localizações sociais que este grupo sempre ocupou. Outro questionamento a ser feito é: será que o simples fato de mostrar os transgêneros já é uma forma de resistência?

Butler (2008) propõe que ao invés de tentar mostrar os transgêneros como ameaçadores das normas sociais - o que sempre fracassou na história das tentativas de promover igualdade deve-se entender os mecanismos pelos quais os transgêneros são colocados em tais posições, a fim de questionar a ordem e a legitimidade de tais procedimentos.

A novidade e o avanço de filmes como Shrek pode ser notado, portanto, por este ser um produto para um grande número de pessoas, com classificação livre e destinado a um público infantil, conferindo-se visibilidade e certa normalidade ao tema do gênero trans, dentre outros. Outro detalhe positivo é que esses personagens estão integrados a grupos sociais onde os gêneros são variados, pautando-se as relações pela amizade, pelo companheirismo e pela solidariedade: Lobo Mau é amigo dos três porquinhos e de Pinóquio, uma das irmãs feias é dama de companhia das princesas e tanto ela como os outros personagens trans referidos fazem parte dos amigos e defensores do casal principal, estando, no grupo dos mocinhos.

Inicialmente, no entanto, o grupo formado pelos transgêneros parece estranho e próximo do abjeto dentro de certo contexto social, pois é um gueto que se assume como diferente ao longo do primeiro filme e de suas seqüências. Mas essa estranheza inicial vai sendo amenizada não só pela presença do humor, mas também por atravessar fronteiras sociais até que o grupo vai sendo aceito dentro do contexto do filme e como representação de algo que está na realidade. Prova disso é a ótima aceitação dos artigos infantis relacionados ao filme que são comerciali- 
zados: as crianças querem ter os bonecos e brinquedos do filme por mais estranhos que os personagens e suas representações de gênero possam parecer.

Não há uma definição rígida da sexualidade de nenhum dos trangêneros em Shrek: não sabemos se Pinóquio é gay, nem com quem Lobo Mau se relaciona sexualmente, e muito menos se a irmãs feias são de fato homens ou mulheres. Claro que em um filme para o público infantil, não é comum a afirmação da sexualidade por parte de nenhum personagem, mas é lícito pensar que ao vermos os personagens principais Shrek e Fiona, que formam um casal heterossexual de Ogro e Ogra, chegando a se casar, a ter uma lua de mel e filhos ao longo dos três filmes, fica claro na mente do espectador que eles têm uma sexualidade heterossexual, repetindo os finais felizes que envolvem os heterossexuais de contos tradicionais como Cinderela, Branca de Neve... Do mesmo modo, o fato de que os personagens transgêneros não serem os protagonistas e não se enquadrarem nos padrões românticos que a indústria do entretenimento exige permite que tais questões não sejam colocadas diretamente para o expectador e que os temas de gênero continuem marginais em relação ao roteiro. Por outro lado, talvez seja esse lugar à margem o que possibilite a preparação progressiva do expectador e o debate em torno das questões, de forma mais amena e mais duradoura conforme Butler (2008) acenou.

A série Shrek recebeu desde seu lançamento, e continua recebendo, muitas críticas de fundo moralista por apresentar essas "sexualidades" transgêneras. Mas por que não questionam a apresentação da "sexualidade" hetero, normatizada em filmes como Cinderela, já que ela está também apresentada de maneira clara? Instituições como a escola legitimam o heterossexualismo afirmando que este é o natural e, muitas vezes, justificam a censura às representações transgêneras e homossexuais por temor que tais representações possam influenciar a sexualidade infantil. Louro (1997) questiona tal pressuposto em seu livro Gênero, Sexualidade e Educação. Para a autora, já que essa identidade heterossexual é considerada natural - e por isso legitimada frente à identidade homossexual dita ilegítima por ser considerada artificial - por que tantos esforços para garanti-la? Se a sexualidade heterossexual é a natural, precisa temer a apresentação de outras sexualidades? 


\section{Transgênero e educação}

Pode parecer, à primeira vista, que refletir sobre o tema dos transgêneros e sua relação com a educação se resume apenas a pensar na área de educação sexual. Mas, se considerarmos o grande número de pessoas que não correspondem a estereótipos do que é considerado "normal" dentro do gênero, como gays, lésbicas, travestis, transexuais, bissexuais, drags estamos tratando de outra forma de pluralismo, não somente o cultural, mas também o sexual, dentro da sociedade. Isso é agravado pelo fato de que sabemos que as pessoas que não se enquadram nos gêneros descritos como "normais" na sociedade podem sofrem sim por causa das questões sexuais. Mas os lugares onde mais essas pessoas precisam de apoio são àqueles que concernem à educação e ao trabalho, pois é justamente nesses lugares que os indivíduos exercem o poder social. Como se sabe, é geralmente nesses lugares que os transgêneros vêem restringido seu campo de atuação e se tornam marginalizados.

Imagine qualquer um dos personagens transgêneros representados em Shrek ocupando uma escola como aluno, como professor, como funcionário. Como ele seria tratado? A não ser que não venha à tona sua sexualidade, ou que ocupe, como nas representações do filme, um espaço limitado dentro da sociedade, reduzindo-se ao lugar do estranho, do abjeto e o espaço da diversão e do humor, o transgênero ainda não tem um espaço para se expressar e desenvolver livremente sua identidade. Além disso, como afirma Louro (1997), independentemente do gênero do indivíduo, ele tem que lidar com gêneros e sexualidades diferentes dos seus, possivelmente até mesmo no interior de suas próprias famílias. Ou ainda, como lembra Butler,

o sujeito é constituído através da força da exclusão e da abjeção, uma força que produz um exterior constitutivo relativamente ao sujeito, um exterior que está, afinal, "dentro" do sujeito, como seu próprio e fundante repúdio.(BUTLER 2008, pag.18)

Então mesmo que seja para perceber-se no lugar da separação e da diferença e de compreender o outro como algo que não se é, os indivíduos e seus respectivos gêneros se encontram e são obrigados a conviver. Do mesmo modo, não há como se formar uma identidade sem se apresentar a ela questões de gênero e de sexualidade, como também não existe inocência sobre os transgêneros. Ou seja: assim como não há como separar na vida um tipo ou outro de constituição de gênero, não há também como proteger as pessoas das re- 
presentações que as cercam por todos os lados. Por que então não emancipar os indivíduos para essas representações? Lidando não com idéias prontas, nem com o que é considerado certo e errado, mas deixando as pessoas no espaço da incerteza, da insegurança, do questionamento do outro e do auto-questionamento. Afinal, como propõe Sedgwick (1997, p.53), "o projeto mais promissor parece ser o estudo da própria incoerência”.

Dentro de uma sala de aula, em uma cidade onde a maioria das pessoas tenha acesso a televisão, a aparelhos de DVD, a DVDs, é provável que boa parte dos alunos já tenha assistido ou tido algum contato com Shrek, que já passou muitas vezes, inclusive, na TV aberta. Tanta exposição demonstra o quanto Shrek é primordialmente um produto da indústria cultural, que necessita da mídia para sua promoção e publicidade - daí os altos investimentos em propaganda que a exibição do filme exige - resultando, afinal, numa produção que atinge um número imenso de pessoas, provenientes de diferentes classes sociais, de variados graus de instrução e de diversas faixas etárias. E é justamente essa capacidade de atingir a todos em seu conjunto ea cada um em sua individualidade que justifica o uso de um produto como Shrek na escola.

Ao usar um produto da cultura visual que todos conhecem é mais fácil e pode servir, inclusive, para aumentar a auto-estima do educando que se identifica com o filme e se sente participante dele. Uma sugestão de atividade poderia ser a utilização do filme para discussão em torno das identidades trans dos personagens de Shrek em momentos em que o filme esteja programado para passar na televisão, usando como aliado o meio de comunicação de massa que tem sido considerado como um grande inimigo da educação.

Aproveitar os momentos em que o filme esteja em exibição na TV aberta serve também como alternativa para escolas que não dispõem de recursos como um retroprojetor ou um aparelho de DVD, nem tempo suficiente para passar o filme e ainda desenvolver uma atividade a respeito.

A atividade proposta consistiria, então, em acertar que todos vissem o filme como um dever de casa e depois seria feita uma reflexão na escola, a partir de perguntas abertas elaboradas pelo professor e debatidas pelos alunos a respeito de tais personagens. Tais discussões deveriam contemplar também a própria vida dos alunos, incluindo-se aí o gênero e a forma como o tema 
é tratado, visando desenvolver um maior respeito pelas diferentes identidades que podem encontrar no mundo. Além das questões relacionadas aos gêneros e às identidades dos personagens, foco principal deste artigo, outras questões poderiam ser debatidas a partir do uso de um filme como Shrek na escola, tais como: as diferenças étnicas e raciais, a abjeção, classe, os padrões de beleza, entre tantos outros.

\section{Referências bibliográficas}

BUTLER, Judith. Problemas de gênero: feminismo e subversão da identidade. $\mathfrak{1}^{\mathrm{a}}$ ed. São Paulo: Civilização Brasileira, 2003. 240 p.

BUTLER, Judith. Cuerpos que importan: sobre los limites materiales y discursivos del sexo. $2^{\mathrm{a}}$ ed. Buenos Aires: Paidós Entornos, 2008. $347 \mathrm{p}$.

LOURO, Guacira Lopes. Gênero, sexualidade e educação: uma perspectiva pós-estrutalista. 9a ed. Petrópolis: Vozes, 2007. 179 p.

LOURO, Guacira Lopes. O corpo educado: pedagogias da sexualidade. $2^{\mathrm{a}}$ ed. Belo Horizonte: Autêntica, 200o. 175 p.

SEDGWICK, Eve Kosofsky. Epistemologia do Armário. Cadernos Pagu. Campinas, v.28, p.19-54. 2007. Disponível em: <http:// www.scielo.br/scielo.php?script=sci_arttext \&pid=So104$83332007000100003 \&$ lang=pt $>$. Acesso em 6 de maio de 2006.

SHREK. Direção: Andrew Adamson. Roteiro: Terry Rossio. Dublagem: Mike Myer; Eddie Murphy; Cameron Diaz e outros. 2007. DVD(92mim).

SHREK, 2 . Direção: Andrew Adamson, Kelly Asbury. Roteiro: Andrew Adamson. Dublagem: Mike Myer;, Eddie Murphy; Cameron Diaz, Antonio Bandeiras e outros. 2004. DVD(92 mim).

SHREK, Terceiro. Direção: Chris Miller e Raman Hui. Roteiro: Andrew Adamson. Dublagem: Mike Myer; Eddie Murphy; Cameron Diaz e outros. 2007. DVD(92mim). 


\section{BELIDSON DIAS}

É professor da UnB e orientador de Alice Lara no Projeto de Bolsas de Iniciação Científica -PIC-UnB. Ph.D em Estudos Curriculares - Arte Educação, University of British Columbia Canadá (2006). Mestrado em Artes Visuais - pintura na Manchester Metropolitan University (1992) e Chelsea College of Arts \& Design (1993) Inglaterra.

E-mail: belidsonn@gmail.com

\section{ALICE MARIA VASCONCELOS LARA}

É aluna do 9o semestre da graduação em licenciatura e bacharelado em Artes Visuais da Universidade de Brasília- UnB, e é aluna bolsista do PIC-UnB. Já trabalhou como mediadora cultural no Espaço Cultural Contemporâneo -ECCO em Brasília e expôs na $27^{\circ}$ Bienal de São Paulo como artista participante do projeto "Sabores y Lenguas".

E-mail: alicemvl@yahoo.com.br 